\title{
"No lo suelen llamar Arte, pero lo es". Estrategias y modos artísticos en Jusep Torres Campalans, de Max Aub
}

\author{
José María de Luelmo Jareño \\ Universidad Politécnica de Valencia (España) \\ jolueja@pin.upv.es
}

Resumen: Uno de los rasgos más destacados de Jusep Torres Campalans, de Max Aub, es sin duda el hecho de evidenciar y cuestionar ciertos atributos de las vanguardias artísticas mediante recursos propiamente vanguardistas. Al habitual énfasis en la transversalidad de la novela o en su estructura cubista —un calificativo que, aun siendo adecuado, requiere ser sometido a revisión-, el artículo añade el análisis de características típicas del arte moderno que se hallan igualmente presentes pero apenas han sido tomadas en cuenta, tales como la adopción de metodologías basadas en el par destrucción-creación, la consideración de la obra como un dispositivo abierto o la afinidad del resultado material con el llamado libro de artista.

Авsтract: One of the salient features of Jusep Torres Campalans, by Max Aub, is the fact of stressing and questioning certain attributes of the avant-garde by using resources that are modernist in themselves. To the common emphasis on the interdisciplinarity of the novel or on its cubist structure - a qualification which, although adequate, needs to be subjected to revision-, this article adds the analysis of some typical characteristics of modern art that are also present in it but have hardly been taken into account, such as the adoption of methodologies based on the destruction-creation complex, the consideration of the work as an open device or the affinity of the material result with the so-called artist's book.

Palabras Clave: Max Aub; Jusep Torres Campalans; vanguardia; novela de artista; libro de artista.

KeYwords: Max Aub; Jusep Torres Campalans; avantgarde; artist's novel; artist's book.

FECHA DE RECEPCIÓN: 24 de septiembre de 2014

FECHA DE ACEPTACión: 17 de abril de 2015

\section{El caso Jusep Torres Campalans}

Nunca me tomé completamente en serio; siempre hubo, gracias al cielo, cierta distancia entre mi obra y yo. A este alejamiento no lo suelen llamar Arte, pero lo es.

Max Aub (1967: 38) 
To por sobradamente conocido puede obviarse un breve esbozo del 1 caso Jusep Torres Campalans, siquiera sea a modo de comienzo y como marco general. En medio de una gran expectación generada por el diario Excélsior, que despacha siete artículos anticipatorios en apenas un mes, el 2 de julio de 1958 se inaugura en la galería que el diario posee en la capital mexicana una exposición de óleos, acuarelas y dibujos de Jusep Torres Campalans, artista recientemente fallecido de quien nada se sabía hasta el momento. Las expectativas de los cenáculos culturales se ven no sólo satisfechas sino superadas con creces, siendo que a la luz del conjunto de obras el pintor catalán aparece como un eslabón perdido en la historia del arte moderno, como un verso suelto que habría sentado nolens volens las mismísimas bases del cubismo. Max Aub, organizador de la muestra, declara haber dado inopinadamente con Campalans en una visita a Chiapas, lugar donde se retirase en 1915 huyendo del faranduleo parisino, del hastío vital, de la contienda mundial y quién sabe si de sí mismo. Tirando del hilo de un par de charlas que estimularon su curiosidad al punto de mutarla en compromiso, Aub habría ido trazando la peripecia del artista y reuniendo el vasto conjunto de materiales que integran tanto la exposición como la publicación correspondiente, un ambicioso volumen que sanciona documentalmente el hallazgo y cuyo elevado precio no impide que la tirada de miles de ejemplares se agote en cuestión de días (Anónimo 1958a: 9).

Sin embargo, poco tiempo tardará en confirmarse lo intuido desde el primer momento, esto es, que todo lo concerniente al fenómeno Jusep Torres Campalans es rigurosamente incierto y que semejante individuo no ha existido jamás en carne y hueso. En el suplemento cultural del diario Novedades del 14 de julio, en efecto, Aub confiesa haber extendido sus habilidades dramatúrgicas más allá de lo estrictamente teatral y se reconoce responsable de la descomunal engañifa desde la primera idea hasta su forma expositiva y de los cuadros mismos a la gestión del conjunto de complicidades que arropa la iniciativa (Anónimo 1958b: 1). Forzoso es mencionar, de entre ellas, la impagable contribución de Jaime García Terrés y Carlos Fuentes, autores de un folleto de dieciséis páginas donde, bajo el nombre de Galeras, se recoge "lo publicado y censurado de las opiniones" (García Terrés 2000: 195) de una veintena de periodistas, intelectuales y artistas acerca del pintor. No es poco mérito que ambos escritores logren imitar en piezas de distinta extensión el tono característico de, entre otros, Elena Poniatowska, Octavio Paz o 
Xavier Icaza, y aunque este engaño por delegación, esta sublime "imitación dentro de la imitación", marca un hito dentro de la mise en scène urdida por Aub, es sólo uno de tantos, como se verá.

Sacando rédito de la martingala promovida en su seno, Excélsior va dando cumplida noticia de las secuelas del caso, que como es lógico no paran de sucederse: lo mismo acoge la carta enviada por una de las víctimas directas - un tal Francisco Camps Ribera, comprador de uno de los cuadros, que en su descargo aduce que las obras en exposición le "parecieron excelentes y dotadas de una sensibilidad poco común" (Camps 1958: s. p.) — ${ }^{1}$ que atiza el fuego con crónicas sensacionalistas del tipo "El escándalo artístico de J. T. Campalans" (Anónimo 1958c: s. p.), propala el bulo de que el auténtico autor de los cuadros es nada menos que André Malraux — quien habría dado en imitar a los pintores que iba incorporando a su ensayo El museo imaginario (Zendejas: 8) — o da cabida a airados artículos como el de Margarita Nelken, cuyo titular “¡Respeto al arte!” no deja lugar a dudas sobre el cariz de su queja (Nelken 1958: s. p.). Precisamente los argumentos esgrimidos por la antigua contertulia de Aub nos sitúan sobre la pista de las implicaciones de la fabulosa empresa promovida por éste y permiten caracterizar el artefacto en su conjunto, puesto que atañen a los tres grandes componentes artísticos puestos en juego, el teleológico, el escénico y el morfológico, núcleos de estudio de este trabajo aunque, como se verá —y no por capricho, sino por necesidad-, de manera un tanto campalasiana, es decir, abierta y desigual.

\section{Fines CRÍticos, MEdios ARTísticos}

Aunque mucho se ha escrito acerca de los propósitos que persigue Max Aub al concebir y desarrollar la operación Jusep Torres Campalans, para Nelken la cosa no admite dudas: nos hallamos frente a una burda comedia del arte de vanguardia, ante una cruel banalización de aquella

\footnotetext{
${ }^{1}$ Este y otros artículos de prensa de la época que se irán sucediendo han sido consultados en la sección Reseñas. Obras de Max Aub 1933-1973, Caja 49: Jusep Torres Campalans del archivo custodiado en la Fundación Max Aub de Segorbe (Castellón, España). El escritor recortaba y guardaba en carpetas dichas reseñas haciendo constar el medio y la fecha pero no así el número de página; de ahí la clave s. p. (sin paginar), que mantenemos.
} 
"etapa heroica del arte no ya sólo francés, sino universal" (1958: s. p.), que precisamente sustenta su heroicidad en "los sacrificios, miserias y mofas sufridas por un puñado de renovadores de las tendencias pictóricas occidentales" (1958: s. p.), es decir, en maltratos parejos al que ahora se le está infligiendo. Nelken detecta en todo el asunto un golpe de mano contra la modernidad, otro más, "ya que las carcajadas ante los maestros de la llamada Escuela de París, símbolo de fariseísmo pequeño burgués, datan de varios lustros y no hay hoy, ni en París ni en ninguna parte, nadie medianamente culto que se atreviera a tomar a chacota $-\mathrm{y}$ mucho menos para utilizar una publicidad de bajos vuelos-, ni a un Picasso ni a un Braque" (1958: s. p.). Con el arte de vanguardia no se juega, decreta la intelectual española,

no es tema que pueda prestarse a bromas ni tampoco que pueda servir para que se abroquelen en sus convencionalismos por demás utilitarios los que, en el México de hoy, y con vistas a los encargos en dólares, pretenden, a la desesperada, tapar el sol con un dedo, o sea cerrarle el paso a la bocanada de aire puro de las corrientes renovadoras, antítesis de las superficiales representaciones folclóricas tenidas por expresión de nuestro pueblo [...] No; el arte practicado con devota dedicación no es cosa de broma, ni tampoco puede servir de burla para una publicidad de conspirata en defensa de la pintura convencional (1958: s. p.).

De poco sirve que en el "Prólogo indispensable", texto que abre la obra, Aub sostenga que no "hay en estas páginas nada que pueda suponerse crítica de la pintura moderna" (1958: 18): la sentencia es firme y viene dictada, precisamente, por una crítica profesional que se siente atacada en su fuero interno y para defenderse de la supuesta iconoclasia maxaubiana no duda en servirse de una acción iconoclasta en grado más extremo, esta es, una furibunda embestida contra la alianza representación folclórica-pintura convencional en lo que de enemiga tiene de todo afán de progreso.

Fácilmente advertimos que este contraataque se plantea en términos vanguardistas en su más estricto sentido, dado que el desprecio hacia la tradición constituye el mandamiento número uno de todo catecismo moderno y ya en 1909 los futuristas lo incluían en el suyo bajo el nombre de antipassatismo, aunque a Nelken parece escapársele que el objetivo primordial de Aub no es otro sino exactamente el mismo, 
atentar contra lo instituido, tomando como tal no ya los viejos usos y costumbres del pueblo o de la academia sino la tradición de lo nuevo, la mitología de una modernidad cuyo Olimpo recién estrenado desprende, a fuerza de sacralización, aires ya respirados. No se le oculta este refinamiento, por el contrario, a críticos como Pierre Mazars, cuando subraya el modo en que "todas esas exégesis digna, piadosa, solemnemente dedicadas a unos pintamonas de quienes nadie hablará dentro de veinte años, esas críticas metafísicas que pretenden que se acepte no importa qué, Max Aub las ha fijado como su objetivo" (11). De hecho, desdiciendo el citado prólogo - pieza que cumple, como todo en este entramado, un cometido funcional-, Aub reconoce en algún lugar que "no tendieron a más mis medios, como no fuera - de paso- a enseñar, con tan buen ejemplo, el cobre de tanta farsa pictórica montada en oro" (1970a: 1). No parece conforme Aub con que posiciones de poder, intereses comerciales o estamentos acreditados — la academia, la crítica y la historiografía artísticas - atrapen aves al vuelo y decreten qué hay en ellas de bueno, qué de valioso y qué de potencialmente duradero, y es a poner en evidencia estos manejos que iría destinada una patraña cuya efectividad se fía justamente al crédito que merecen el organizador y las prestigiosas personalidades e instituciones involucradas en ella, vale decir, al peso específico de una autoridad competente que, lo quiera o no, se está cuestionando a sí misma desde el momento en que accede a colaborar con el autor.

Ahondando en su querella, Nelken sostendrá que nada hay de refinado en el asunto, entre otras cosas porque "copiar deformándola un poco la obra de un pintor de vanguardia es cosa fácil, al alcance de cualquiera" (1958: s.p.). Sin embargo, su descalificación se torna de nuevo argumento a favor al reconocer implícitamente en la acción maxaubiana un desbordamiento de los límites de la vanguardia con sus propios procedimientos, siendo como es notorio que sus integrantes se consagraron a la mímesis distorsionante y al desvío (détournement) en tanto que procedimientos elementales de creación, cuando no al alumbramiento de heterónimos, espantajos funcionales o personalidades reales de carácter ideal. Viene al caso, sin ir más lejos, Arthur Cravan, boxeador aficionado y escritor bohemio en el que los vanguardistas parisinos quisieron ver a un creador que hibridaba ingenuidad y raciocinio, rudeza y pujanza creativa, y mucho de esta suma de aparentes contrarios se manifiesta en Jusep Torres Campalans, un modelo con el que, según 
Antonio Saura, "Max Aub quiso sin duda confirmar, a través de un collage psicológico, un personaje que respondiera en cierto modo a la imagen de un artista verdaderamente auténtico - e incluso a la de un artista maldito-, un artista puro, como surgido de la matriz popular, azarosamente, por generación espontánea, pero provisto de una fuerte intuición e inteligencia, aunque contradictorio e inmaduro" (96). Hacemos nuestras, en este punto, las palabras de Miguel Corella - deudoras de Rosa María Grillo, quien a su vez refiere a Umberto Eco, en un encadenamiento que demuestra hasta qué extremo es común el maxaubiano hábito de servirse de lo ya existente- cuando afirma que "el personaje Jusep Torres Campalans es, efectivamente, un falso perfecto: falso porque no existió en carne y hueso y perfecto porque la síntesis de rasgos particulares que propone constituye un retrato ideal del artista de vanguardia” (126). ¿De qué rasgos particulares estaríamos hablando, qué pedazos compondrían, en fin, esta literal quimera? De acuerdo con los análisis "forenses" de José Carlos Mainer, que ha diseccionado el personaje pieza a pieza,

Aub construye su personaje sobre un puzzle novelesco de los rasgos fundadores de la estética pictórica moderna: Torres es catalán, como fue Miró; conoce el campo (como hicieron Miró o su casi homónimo Torres García) y es profundamente religioso, como fue Van Gogh; ostenta una naturalidad casi cínica de comportamiento que puede ser remedo de la de Picasso; vive su descubrimiento del arte en París, como todos los hombres de su generación, y su per3odo ascendente y esperanzado concluye en 1914 con el estallido de la guerra; ya al final de su trayectoria, busca en la tierra de México la espontaneidad vital que Europa le niega, como un día hizo Gauguin en Polinesia o como haría el surrealista Antonin Artaud en el mismo lugar que Torres (79).

No se conforma Aub con ensalzar la vida de este o aquel artista en particular, a la manera de ciertos biopics (biographical pictures) muy en boga por entonces —Moulin Rouge, Lust for life o Montparnasse 19 son tres buenos ejemplos, como también lo es, aunque muy distinto, Le mystère Picasso, donde el artista malagueño se interpreta a sí mismo y se concede una distancia a medio camino entre la cosificación y la idealización-. No, para su mistificación Aub no empleará una única fragancia sino que destilará notas de distinta procedencia y las 
condensará en una sola que evoque todas a la vez y ninguna en particular, como si las cinco Memorias biográficas de pintores extraordinarios que William Beckford publicase en 1770 se fusionaran entre sí. "Aub construye la figura de su personaje — reitera Corella — a partir de mil imágenes tomadas de lo real, pero también a partir del prototipo ideal" (131), es decir, de una visión genérica que resulta de acrisolar variables tipológicas y establecer constantes dentro de la diversidad, y si nadie ha llegado tan lejos en la recreación del carácter y las aspiraciones vanguardistas es porque pocos poseen un conocimiento tan exhaustivo del tema, de suerte que "este artificio engañoso se convierte en verdadero por su capacidad para permitir la legibilidad, la visión clara, de una realidad histórica” (125).

No en vano entre los años veinte y treinta el quehacer de Aub como viajante de comercio le lleva a realizar numerosos viajes por Europa y a conocer de primera mano, ayudado de su condición políglota, las tendencias artísticas del momento, circunstancia a la que suma su participación en los círculos culturales más pujantes del ámbito español y, ya en los ańos cuarenta, su contacto con la vigorosa modernidad mexicana. Subraya Carlos Pérez que a toda esta experiencia directa añade un extraordinario bagaje de lecturas, pues "los títulos conservados en su biblioteca confirman ese interés que el escritor mantuvo, durante toda su vida, por el arte y la literatura de vanguardia: de Marinetti, Cocteau, Max Jacob y Ramón Gómez de la Serna a Le Corbusier, Michel Seuphor, Doisneau y Álvarez Bravo", y es por situarse a caballo de ambas disciplinas por lo que "Max Aub se alineó con los creadores que dinamizaron — conjugando la ironía, la elegancia, la sabiduría y el ácido sulfúrico- las artes y las letras modernas. Entre otros, con Tristan Tzara, Picabia y Raymond Queneau" (71). Si bien Juan Manuel Bonet incide asimismo en este aspecto al resaltar que el intelectual español "se incorporó, de un modo absolutamente original, único, a la saga de escritores-pintores de nuestro 27, a la que pertenecieron también Federico García Lorca, Rafael Alberti, José Moreno Villa” (14), es necesario mostrar, a la luz de lo señalado hasta aquí y del componente formal que ahora analizaremos, cómo Max Aub va mucho más allá, en qué grado es - sirviéndonos del apelativo que recibiera en atención a su elevada productividad- más aún. 


\section{UN MODELO DE SINCRETISMO}

Que Aub inaugura una nueva posición dentro del campo de fuerzas literatura-pintura significa, de entrada, no una simple toma de distancia con respecto a los referentes habituales sino una superación crítica de éstos mediante la creación de un insólito modelo sincrético. Quizá nada mejor para definir Jusep Torres Campalans que recurrir a las palabras empleadas por Aub para referirse a su otra gran semblanza artística, la consagrada a Luis Buñuel, cuando la califica de "algo híbrido, como han venido a ser hoy, en general, las obras de arte: teatro que no es teatro, novela que no es novela, poesía que no es poesía" (1985: 20). Fiel a esta definición del arte literario contemporáneo, Jusep Torres Campalans poseería tintes artísticos merced a un carácter interdisciplinar claramente constatable en, al menos, tres planos superpuestos:

- Al constituirse en réplica optimizada de las mejores monografías artísticas, es decir, al basarse en ciertas publicaciones especializadas que acaban siendo aventajadas en punto a complejidad interna y cuidado editorial.

- Al ofrecerse como un retrato moderno del artista moderno que desatiende los recursos al uso y cataliza materiales de distinta índole —datos históricos, testimonios personales, cuadernos de trabajo, imágenes, etc., pero también espacios, tiempos y modalidades discursivas y lingüísticas - bajo la forma de un collage de inspiración e intención cubista.

- Al actuar como un libro de artista encubierto donde Aub desdibuja los límites entre lo verdadero y lo falso y entre lo propio y lo ajeno e instaura un nuevo cauce heteronímico para su actividad plástica personal.

Como quiera que el grado de hibridación en juego hace difícil desgajar cualquiera de esos aspectos sin convocar a los otros, y analizar la naturaleza formal de Jusep Torres Campalans pasa por atender simultáneamente a todos ellos, ésta será la opción, ya lo anunciábamos, que desplegaremos a continuación. Jusep Torres Campalans es una ficción disfrazada de documento, un remedo crítico de las ediciones de arte y el resultado de una acción artística individual, pero, por encima de todo, 
el extraordinario desbordamiento de cada uno de esos aspectos gracias al concurso necesario de los demás.

Puestos a afrontar las características del componente editorial del fenómeno Campalans, bueno será retomar la invectiva de Margarita Nelken y constatar cómo su tono se eleva al denunciar la complicidad de la editorial encargada de publicar el libro, Fondo de Cultura Económica - sello de máximo prestigio e inmejorable aval, otro más, para acreditar la existencia del tal Campalans-, pues "lo más lamentable en el asunto - aduce - es que una editorial tenida por tan seria como el Fondo de Cultura Económica se prestara a ese género de publicidad [...] por cierto que en descarado remedo, en su formato y presentación, de las Ediciones Skira" (1958: s. p.), es decir, profanando otro símbolo sagrado de la modernidad. Bien podía darse por satisfecho un Aub que ya en sus apuntes de enero de 1957, fecha de comienzo del libro, se planteaba "publicarlo como un libro de Skira" (Rodríguez: 52) y recogía ahora los frutos de su afán mimético, y frutos no ocasionales, por lo demás, pues Juan Manuel Bonet declara que "quienes frecuentamos las librerías de viejo y sus ofertas por correo —o, más recientemente, Internet-, sabemos que el libro, tanto en su edición original como en sus traducciones francesa y norteamericana, da el pego: en más de una ocasión lo hemos visto catalogado en el apartado de monografias de arte" (14). El propósito de servirse de Skira como modelo confirma el hondo conocimiento maxaubiano del panorama editorial del momento: si pocos sellos podían ostentar una legitimidad vanguardista semejante -Albert Skira había editado en los años treinta la mítica revista surrealista Minotaure y libros de arte con grabados originales de Picasso, Matisse o Dalí-, ninguno era capaz de hacerle sombra en términos de calidad gráfica y excelencia formal. Ignacio Soldevila apunta que Aub pudo inspirarse en los rasgos del Picasso de Maurice Raynal (1973: 151), y claramente así es, porque la monografía del especialista francés, cuarto volumen de la colección Le gồt de notre temps, se parece en casi todo a Jusep Torres Campalans (cfr. Raynal 1953). Si ya las dimensiones generales así lo evidencian, las encuadernaciones que hallamos bajo las respectivas sobrecubiertas ilustradas no pueden ser más parejas: tela de lino de grano medio (algo más oscura en la edición mexicana) y estampación a color tanto en el lomo (Picasso en rojo, Jusep Torres Campalans en negro) como en el centro de la cubierta (en un caso la característica $S$ en fuente Futura condensada de Skira, y 
en el otro las iniciales JTC superpuestas y formando un anagrama en verde vejiga). Aub contará con José de la Colina y Jasmin Reuter, de Encuadernaciones Progreso, para consumar la tarea, y con Gráfica Panamericana y Helioméxico para replicar las extraordinarias reproducciones que hacían únicas en su género las ediciones de la casa suiza. Si en libros como Picasso asombra todavía el grado de fidelidad a los cuadros originales que presentan las fotografías - perfecta rendición de los detalles, latitud impecable, extraordinario rango tonal-, impresas en papel cuché y adheridas por uno de los bordes a páginas en blanco, de forma que relieve y brillo las hacen emerger del papel mate y contrastar con la monocromía del pie de texto, qué asombro no ha de producir que el equipo editorial lograse imitarlas con semejante exactitud e incluso se arriesgase a hacerlas convivir a menudo con el texto. Forzoso es reconocer que el éxito de la empresa debe mucho no sólo a la amplia experiencia acumulada a pie de imprenta por Aub sino al buen hacer del coordinador de edición, el holandés A. A. M. Stols, quien venía de publicar en Europa a prestigiosos escritores -Alfonso Reyes, entre ellos-, coordinar revistas culturales y ediciones bibliofílicas de la mano de Valery Larbaud, e incluso mantener un sello propio, Halcyon Pers. ${ }^{2}$

No es éxito pequeño que "bajo la dirección del maestro Stols" (así indica el colofón del libro) se lograse tal parecido con ellas, pero conviene subrayar que Jusep Torres Campalans no es mera mímesis material de la colección Le goût de notre temps sino también, o ante todo, estructural. El Picasso de Raynal, por volver al caso, se abre con un apartado de "Dates et concordances" donde año por año se consignan datos de la vida del pintor acompañados de los hechos históricos más relevantes en el campo del arte (nacimiento de Marcel Duchamp en 1887, fundación del Museo de Arte Moderno de Nueva York en 1929, etc.), al que siguen un sucinto "Avertissement de l'éditeur", una prolija descripción de la trayectoria de Picasso dividida por etapas ("La jeunesse de Picasso a Barcelone", "L’epoque nègre", "Un retour a la plastique pure"...) que ocupa el grueso del libro, una bibliografía sumaria, una relación de exposiciones seleccionadas y un índice de nombres. Prescindiendo de estas tres últimas secciones, Aub se servirá del mismo armazón pero lo desbordará largamente, porque a los apartados equivalentes (aquí titulados "Prólogo indispensable", "Anales" y "Biografía") sumará uno

${ }^{2}$ Cfr. los capítulos iniciales de la monografía de Van Dijk 1992. 
inicial con citas de Gracián, Ortega y un tal Santiago de Alvarado, otro de agradecimientos donde también se mezclan nombres reales y ficticios, un aparato erudito — que sigue la misma pauta - compuesto por artículos sobre la idiosincrasia artística y política española y sobre el propio Campalans, una breve recopilación de declaraciones suyas a la prensa parisina en los años 1912-1914, un amplio conjunto de pensamientos y sucedidos del artista ordenados por años y temas (el llamado "Cuaderno verde", claramente inspirado en El día y la noche de Georges Braque), un capítulo donde se refieren sus encuentros chiapanecos con el pintor ("Las conversaciones de San Cristóbal", anotado a su conclusión con el correspondiente bloque de referencias eruditas), y un catálogo razonado de obras en el que se nos dice trabajaba el joven crítico irlandés Henry Richard Town, con vistas a la primera exposición de Campalans en la Tate Gallery de Londres, justo antes de que un bombardeo alemán acabase con su vida y con su proyecto en 1942 .

$\mathrm{Si}$ atendemos a una entrada del 9 de agosto de 1955 en el diario de Aub, comprobaremos hasta qué punto tenía clara desde un primer momento la estructura del proyecto y el margen de maniobra que ésta le iba a permitir:

Nace Jusep Torres Campalans [...]

Escribirlo todo como una monografía 'acerca de...'.

Entrevista. Vida (falsa).

Estética (falsa) $[\ldots]$

Publicarlo como una monografía con reproducciones (1998: 267).

En una entrada posterior, iniciada ya la redacción del libro, esbozará con trazo grueso el retrato del artista y remachará tanto el plan de trabajo como sus "enormes ventajas: de un lado anales, que permitan ofrecer la época, luego la biografía, sin rebabas: puro cuento" (Rodríguez: 52). Según este presupuesto, historia y ficción no serían sino variantes de lo mismo, pura concordancia, de ahí su participación en pie de igualdad y de ahí, sobre todo, su permutabilidad. Como si empleara a modo de soporte una de las típicas estructuras reticulares de Joaquín Torres-García - artista con el que Jusep Torres Campalans guarda una fuerte similitud, más allá de la del nombre-, Aub se servirá de la ordenación característica de las monografías de arte — contexto histórico, biografía, obra, datos técnicos, etc.— para 
engastar piezas legítimas y piezas espurias de distinta entidad que se corroboran y desdicen constantemente. En palabras de Antonio Saura, "como en un especial juego del ratón y el gato, se nos ofrecen datos verídicos entremezclados con falsos datos y se nos ocultan otros, aquellos justamente que nos podrían confirmar la realidad del personaje" (98), de suerte que apenas cuenta uno con asideros firmes y sabe a qué atenerse. Quizá después de todo no resulten necesarios y la mejor opción sea dejarse llevar por la corriente del libro, pues, como dijera Jean Cassou, cómplice privilegiado de Aub, “¿qué distinción establecer entre dos realidades que se hubiesen decretado real la una e imaginaria la otra? Picasso era verdadero. Y es imaginario como Campalans" (1961a: 1).

Cierto es que Aub armará otras novelas de artista semejantes a Jusep Torres Campalans en cuanto a modularidad y ambigüedad. Si Vida y obra de Luis Álvarez Petreña, que conoce una primera parte en 1934 y sendas ampliaciones en 1964 y 1970, se basa en la patraña del legado textual de un escritor sin éxito al que se añaden cartas de sus allegados, opiniones de lectores y hasta anotaciones y testimonios del propio Aub, La calle de Valverde, de 1964, cuaja un sinnúmero de fragmentos vitales que van del ficticio pintor Miralles a los tertulianos del momento pasando por una amplia galería de caracteres, todo ello abrochado hacia el final del libro con el comentario del apócrifo hispanista André Barillon. ${ }^{3}$ Lo que en aquella novela se resuelve mediante una adición de elementos complementarios prolongada en el tiempo, en ésta se traduce en arborescencia y entrecruzamiento interno, si bien ambas coinciden en su apelación al marco metaliterario como argumento de autoridad y soporte de validez. En Jusep Torres Campalans, por el contrario, no hay desdoblamiento que valga, no hay una carne narrativa arropada por elementos metaliterarios. No puede hablarse propiamente aquí de texto, sino tan sólo de paratexto, por la sencilla razón de que todo el marco al completo - prólogo del autor, datos de toda índole, citas eruditas, testimonios y demás- actúa como certificado de autenticidad o derogación de sí mismo mediante un juego cruzado de reflejos: esto sostiene o desbarata aquello y aquello, a su vez, justifica o inhabilita lo de más allá, sin aparente

${ }^{3}$ Sobre el fascinante universo de los apócrifos en la obra maxaubiana, cfr. Rosell 2012 y Oleza 2013. 
solución de continuidad y sin que nada subyazca de manera estable y de una vez por todas.

Con todo y con eso, el procedimiento maxaubiano desborda de largo su funcionalidad paródica y crítica para constituirse en la mejor forma de pintar el retrato de un artista poliédrico, escurridizo y, en fin, provisional. Es en este punto donde constatamos la justeza del modelo ideal creado por Aub, porque exactamente esos y no otros son los rasgos que caracterizan la vida moderna, la visión inducida por ella y la pintura surgida en su seno: de ahí el carácter extraordinariamente paradigmático de Campalans. ¿Cómo dar cuenta conjunta de un mundo fenoménico que nace, se metamorfosea y se descompone a ojos vistas, de su signo más conspicuo, mutable donde los haya —el arte de vanguardia- $y$, por encima de todo, de un personaje en cuya condición vital concurren ambos aspectos, si no es mediante un sistema de registro y un modo de presentación dinámicos en sí mismos? Y así las cosas, puesto que la forma ha de ser al contenido, ¿cómo no mirar hacia la pintura moderna, cómo no buscar en ella una solución de compromiso si a fin de cuentas es a su alrededor que nos estamos moviendo? $\mathrm{Al}$ igual que hicieran numerosos escritores antes que él, Aub parece inspirarse en cierta pintura convencido de que, indica Corella,

la forma en que se va escribiendo y se va haciendo el personaje no puede ser ya la del narrador omnisciente y la narración lineal, sino un procedimiento técnico que permita mostrar la forma misma de la construcción: por agregación y yuxtaposición de partes, por superposición de planos y puntos de vista, un procedimiento y una mirada cubista (133).

Aunque es bien recurrente la apelación al cubismo a la hora de definir Jusep Torres Campalans ${ }^{4}$ — una afinidad señalada por el propio autor, cuando confiesa haber acometido la "apariencia del biografiado desde distintos puntos de vista; tal vez, sin buscarlo, a la manera de un cuadro cubista" (Aub 1958: 16)—, rara vez se tiene en cuenta que Aub no sólo recurre a ese movimiento de vanguardia para inspirarse en su modelo multiperspectivista, esto es, en la concurrencia simultánea de visiones di-

\footnotetext{
${ }^{4}$ A este respecto quizá el estudio más clarificador hasta la fecha sea el de Vílchez 2007, a pesar de efectuar un análisis formal de la novela donde el cubismo es empleado más como metáfora que como analogía efectiva y de soslayar las jugosas concomitancias entre las heurísticas cubista y maxaubiana.
} 
ferentes y sucesivas, sino también en su noción netamente fenomenológica de una "creación" del objeto en el acto mismo de la visión, idea según la cual el motivo no preexiste al contacto visual sino que emerge con su concurso y se establece como cosa gracias a él. El personaje ideado por Aub, en efecto, nace durante el proceso de poner en común las distintas piezas, y no antes: al igual que el cuadro cubista es la síntesis de las distintas facetas del objeto, su acta de nacimiento visual y un memorándum ofrecido al espectador para que reconstruya esa génesis por sí mismo; así, Jusep Torres Campalans, ese individuo totalmente desconocido hasta la aparición del libro, adquiere en él y por él carta de naturaleza mediante el encastre de las múltiples visiones parciales que lo refieren. Es así, obviamente, para un lector que va montando como bien puede el puzzle dispuesto por el autor, pero también para éste, incapaz de prever con exactitud qué imagen general puede acabar obteniéndose del encaje de las piezas, si es que él mismo, por mucho que haya concebido y puesto en pie y en circulación al personaje, la tiene.

Si en cada figura novelesca habitan en potencia tantas identidades como lectores pueda tener, qué decir de un Rimbaud pictórico — la fórmula es de Cassou (1961b: 9) — que se nos ofrece rapsódicamente, descoyuntado, sin ensamblar. Un modelo para armar cuyo formato remite a otro de los instrumentos característicos del cubismo y de la vanguardia toda, el collage, por la referida coexistencia de elementos reales y elementos ficticios y, sobre todo, porque los materiales convocados en ese plano de representación que es el libro muestran a menudo bordes bastamente recortados — datos vagos o mal consignados y contradicciones internas, intencionadas o no- $-\mathrm{y}$ huellas del adhesivo empleado en su montaje —elementos ilógicos, circunloquios o argumentaciones que traen a la mente aquello de excusatio non petita, accusatio manifesta-. Sea como sea, nada hay que ocultar: un Aub que confiesa impúdicamente al comienzo de su Luis Buñuel, su otro gran retrato cubista, que no llegaría a completar, que "no queriendo inventar, robé. Es decir, copié, hurte, transcribî" (1985: 18), difícilmente podría pretender esconder las fuentes de su Jusep Torres Campalans. Antes al contrario, que se hagan elocuentes es consustancial a un artefacto vanguardista cuya construcción lleva aparejada un cuestionamiento y una destrucción crítica de los contextos de origen, en el entendido de que son lábiles y relativos y una vez manipulados dejan de ser lo que eran en términos de estabilidad, integridad y fiabilidad. 
Desde luego, dejaron de ser lo que en realidad eran las fotografías insertas en el apartado biográfico del libro. Las pruebas de reparto tomadas en 1938 en Prat de Llobregat (Barcelona) por el equipo de producción de la película Sierra de Teruel, siguiendo indicaciones de André Malraux y del propio Aub, ya no corresponden a campesinos anónimos sino, mediante el sencillo détournement de cambiar a capricho el pie de foto, a los padres leridanos del propio pintor, Genaro Torres Moll y Vicenta Campalans Jofre. Dejó de ser lo que era la fotografía de un espectador de fútbol para pasar a representar, convenientemente retocado, al mismísimo Campalans, inserto en otra, esta vez sí auténtica y hasta célebre - tomada por Juan Vidal Ventosa en 1906- donde se ve a Picasso sentado en un café barcelonés. La imagen viene fechada en 1902 y firmada sin recato por el célebre cartelista, pintor y fotomontador José (Josep) Renau, reconociendo con ello que se trata de una muestra del modelo por excelencia de hibridación realidad-ficción en el que se basa Max Aub, de un montaje vanguardista en sentido estricto, aunque un tanto burdo para ser obra de un Renau que viene de realizar la extraordinaria serie The American Way of Life, dicho sea de paso. En principio ésta es la única contribución plástica ajena en todo el libro: todo lo demás, desde las viñetas a línea insertas en el cuerpo de texto a los cuadros cuidadosamente reproducidos en blanco y negro o en color es, como bien sabemos, obra del propio Aub.

"Los dibujos, ¿qué me cuesta hacerlos? Con intentar copiar a Picasso o a Braque. Mi inhabilidad dará la diferencia", argüía en su diario de 1957 (Rodríguez: 52). En la variada producción pictórica recogida en Jusep Torres Campalans hallamos remedos más o menos logrados de ambos artistas, sí, pero también ecos de Nolde, Matisse o Dufy, quizá en el convencimiento de que su factura característica comprometía menos al autor y le permitía disimular con mayor solvencia esa inhabilidad. Es precisamente el volumen de este tipo de obras de fuerte cromatismo y gestualidad frente al de aquéllas lo que lleva a Fernando Huici a desmentir la convencional adscripción cubista del pintor, alentada como vimos por el propio Aub, en beneficio de una filiación más bien expresionista (39). Atribución constatable a la vista del lenguaje plástico dominante y, de forma aún más elocuente, del lenguaje verbal y los contenidos de su "Cuaderno verde", caracterizados casi en su totalidad por un antiintelectualismo y un primitivismo visiblemente afines a los del expresionismo alemán. "Dejarse llevar, pintar con lo de adentro, a 
ojos cerrados" (Aub 1958: 193), "No pintar ideas" (193), "Ideas, ¿para qué?: todas iguales. Sensaciones, sí: todas distintas" (194), "Para pintar: no pensar. Dejarse ir, llevado por las manos" (195), "Pintar en contra, siempre" (197), "Ni contar, ni explicarse: imponer" (204), "Pintar para mí, para ser, no para otros seres" (206), "No desechar nada, más que la propia obra" (226), "Romper con lo hecho, rompiéndolo" (232), "El arte arde o no es" (188), y así tantas y tantas sentencias a medio camino entre el individualismo radical de un Stirner, el anarcocristianismo - recurrentes son las apelaciones a Dios- y el nihilismo característico de los textos expresionistas.

No puede negarse que muchas de las sentencias, como la última citada, poseen una extraordinaria belleza, de ahí que el gran pintor y escritor Antonio Saura dictamine que "la pintura de Torres Campalans es mejor a través de cuanto se nos dice que de cuanto se ofrece a la mirada [...] A pesar de ser presentado como un mediocre escritor, Campalans resulta ser mejor escritor que pintor, mientras que el creador literario del fantasma, gran escritor, no es más que un mediocre pintor" (94). De hecho, a veces cae uno en la tentación de pensar que Aub ha diseñado un artista a la medida de esa mediocridad, y no al revés, porque la barahúnda de recursos y estilos pictóricos casa mejor con la pasión de un diletante imitando lúdicamente a sus ídolos que con la supuesta integridad de un Campalans cuyo compromiso máximo con la pintura le lleva a repudiar la supuesta inconsistencia de Gris, Van Dongen o Modigliani aunque, a la vista de su producción personal, no parece tener el más mínimo reparo en copiarlos a todos ellos. Pilar Sáenz va todavía más allá al lanzar una pregunta retórica no exenta de polémica: "¿Fue todo el relato de compleja estructura un subterfugio para dar a la luz pública la obra pictórica del escritor Aub? ¿Es este un caso de timidez o de humorismo?” (489). Contra lo que pudiera parecer, la cuestión resulta tan pertinente como difícil su respuesta, porque lo cierto es que algunos testimonios de sus allegados se compadecen mal con las palabras del propio Aub y permiten ver que algo hubo de exhibición discreta, después de todo. En carta enviada el 28 de diciembre de 1958 a Carlos Barral — cuyo comienzo, "siento mucho desengańarle, pero se trata de una novela: J.T.C. no existió nunca —que yo sepa" (1958c: 1), viene a sacar a Barral del equívoco en el que habría caído-, reconoce que "en mi vida pinté más que los cuadros y dibujos ahí reproducidos" (1), afirmación que reitera en su 
siguiente misiva al editor y escritor catalán — "nunca pinté" (1958d: 1) - y en una entrevista con Claude Couffon registrada años después. ${ }^{5}$ También confiesa a Barral - y nuevamente a Couffon- que los cuadros han sido "hechos con tres pinceles de a peso - tres pesetas- y con tintas de escribir a las que añado guache a última hora. Me fueron saliendo en el curso de la novela" (1). Sin embargo, existen indicios de que Max Aub contaría con cierta experiencia en el ejercicio de la pintura a la hora de acometer los cuadros destinados a la exposición y al libro. Así, Bernardo Giner de los Ríos refiere las visitas que Aub solía hacerles en torno a 1947 y recuerda claramente,

verlo aparecer una mańana con algún cuaderno y una larga caja de madera $[\ldots]$ una especie de caja de puros compartimentada que, en lugar de tabaco, contenía un multicolor juego de plumas, con la particularidad de que no eran una o dos sino muchas las piezas que guardaba. Eran plumas norteamericanas bastante baratas, de la marca Esterbrook, que tenían, en la caja de Max, varias virtudes que nos deleitaron un buen rato: estaban llenas de tintas de distintos colores y, además, cada una de ellas cumplía una función caligráfica diferente, ya que las puntas eran intercambiables. [Max Aub] accedió a nuestros ruegos y nos pintó alguna cosa (58-59).

¿Pudo un Max Aub que conocía de primera mano los ambientes de galería y de taller, incluyendo el de Picasso en París, se jactaba de un olfato para la pintura que le llevó a comprar a Ramón Gaya su primera acuarela cuando nadie lo conocía (Aub 1971b: 403), y no viajaba sin su pequeño juego de materiales caligráficos, haber dado el pequeño paso que le separaba de la práctica efectiva de la pintura? Todo lleva a pensar que, siquiera de manera eventual, así fue, aunque lo único cierto es que Max Aub, desdiciéndose a sí mismo — a Couffon declara en la citada entrevista que no volverá a pintar más- siguió pintando más allá de Jusep Torres Campalans, perfecto sosias para dar a ver nuevas obras sin comprometer su prestigio como escritor.

${ }^{5}$ Cfr. Couffon: 184. En el marco de una entrevista concedida a Télé 7 Jours, Aub se presta incluso a ser fotografiado "pintando" — más en concreto, restregando un gouache recién pintado en una charca de su jardín - a fin de recrear el procedimiento seguido en la confección de algunas de las obras. Cfr. Chabrun: 31. 
De entrada, este desdoblamiento va a ampliar notablemente su radio de acción al permitirle actuar en dos planos paralelos modulables a voluntad, tal y como sucede en Juego de cartas (México: Finisterre, 1964), nuevo alarde editorial donde retoma el modelo epistolar empleado en Luis Álvarez Petreña bajo un formato mucho más experimental: si allí las misivas de algunos conocidos dibujaban parte del perfil del protagonista, aquí es la vida entera de un tal Máximo Ballesteros la que se desglosa en cartas (epístolas) impresas al dorso de 104 cartas (naipes de $11 \times 17 \mathrm{~cm}$ ) ilustradas con tintas de colores por Campalans. Fiel a su título, la noción de juego constituye la razón de ser de la novela y justifica su calificación de obra abierta más allá del hecho literal de presentarse estuchada y sin encuadernar, porque al lector corresponderá barajar el mazo e ir estableciendo aleatoriamente la secuencia de lectura - las cartas carecen de numeración o pauta de ordenación alguna- y, en consecuencia, la articulación biográfica del personaje.

Por aquel entonces, sin embargo, el verdadero juego pictórico maxaubiano se estaba desarrollando a cuenta de las secuelas de la exposición y la publicación de Jusep Torres Campalans, y es que, si algo hemos visto del revuelo que el fenómeno levantó en México - y, en menor medida, en España—, el impacto alcanzado en Francia y en Estados Unidos por las traducciones correspondientes apenas se quedó atrás. Dejaremos para más tarde el carácter de ambas y de cuantas les siguieron y nos limitaremos a subrayar en este punto el hecho de que, así como la edición francesa no llevó aparejada exposición alguna, Aub tuvo a bien aceptar la sugerencia del traductor estadounidense, Herbert Weinstock, cuando le propuso que, caso de obrar todavía en su poder los cuadros mexicanos, él mismo "podría gestionar una muestra de ellos aquí en Nueva York en una galería de arte en la fecha de publicación del libro", persuadido como estaba de que "esto podría dar un tremendo impulso al libro y sería además muy divertido" (1962: 1). "Referente a la exposición — responde Aub — estoy completamente de acuerdo. Tengo algunos cuadros, otros están en posesión de amigos, otros se vendieron a la salida de la edición mexicana. Los cuadros se vendieron con un ejemplar del libro a un precio bastante remunerativo. Otros se vendieron en el extranjero y no me será posible conseguirlos pero puedo volver a hacerlos sin mayor dificultad..." (1962a: 1). Y así fue, efectivamente, aunque de lo pintado para la exposición celebrada en la Bodley Gallery entre el 29 de noviembre y el 10 de octubre de 
1962 apenas tenemos constancia gráfica, porque el catálogo editado al efecto sólo contiene descripciones técnicas y la edición del libro en Doubleday, a la que volveremos enseguida, únicamente incorpora reproducciones del material ya conocido. Fernando Huici estima que a los 35 originales mexicanos Aub añadió otros 48 cuadros pintados para la ocasión (38), de los cuales se tienen hoy localizados solamente nueve: cuatro exhibidos en Valencia con motivo de la exposición dedicada a Jusep Torres Campalans en 2000 y otros cinco —uno de ellos regalado en su día a Camilo José Cela por el autor- ${ }^{6}$ que se incorporaron a la organizada en Madrid en 2003. El engranaje edición-exposición, con la consiguiente incorporación de nuevas obras, se diría establecido como pieza necesaria de la maquinaria Campalans si nos atenemos a los planes para la edición del libro nueve años después, en la editorial espańola Lumen, señalados por Aub en carta dirigida a la agente literaria Carmen Balcells:

Yo estoy dispuestísimo a hacer una exposición campalanera. Pero el hecho es que no tengo ningún cuadro y que para sacarlos de aquí sería un verdadero problema, pero estoy dispuestísimo, como te dije a ti y posiblemente a Cesáreo a preparar la exposición en 15 días si me dan los medios para pintarlos y me pagan el viaje con ese fin. Estoy dispuesto, si se cumplen esas condiciones, a regalar a quien sea la producción que "aiga". Te advierto que una porquería, una cuartilla, que tiene mi hija mayor en Inglaterra colgada en el corredor, la han valorado en 100 libras, ¡y sabían quién era Torres Campalans! (1971a: 1).

Vuelve a aparecer aquí la íntima satisfacción de un Aub cuyas obras, por expeditivas que sean — dos semanas para elaborar toda una exposición- y mediocres que puedan parecer, levantan pasiones entre los entendidos en arte porque en buena medida es a ellos, capaces de mutar la arena en oro y la impericia en virtud conceptual, a quienes irían de nuevo destinadas como instrumentos de burla, con la notable diferen-

\footnotetext{
${ }^{6}$ Cela cumplió un destacado papel en la difusión de Jusep Torres Campalans al publicar parte de la obra en una separata de su revista Papeles de Son Armadans. La correspondencia de la época entre ambos escritores no tiene desperdicio, por lo demás: si Cela suele concluir sus cartas pidiendo a Aub que transmita sus respetos al pintor, Aub, por su parte, replica con mensajes del tipo "Jusep Torres Campalans te saluda afectuosamente" (Aub 1958a: 1) o "Saludos de Torres Campalans. Y un gran abrazo" (Aub 1958b: 1).
} 
cia de que esta vez están sobre aviso y se disponen a adquirirlas precisamente por ese motivo. Cabe recordar que nos hallamos en pleno auge de las nuevas estrategias artísticas - happenings, performances, instalaciones y similares - y en un contexto en el que Marcel Duchamp acaba de fallecer y de consolidarse como deidad suprema del arte moderno gracias, entre otras acciones, a enrevesadas empresas artísticas prolongadas en el tiempo, a mayúsculas bromas intelectuales y a la creación de heterónimos como Rrose Sélavy. ${ }^{7}$ En este marco, el arte expandido y los juegos de espejos entre creador, criatura y espectador causan fascinación porque desdibujan los contornos que tradicionalmente separaban arte y praxis vital e inauguran una insólita dimensión donde realidad y ficción constituyen una misma entidad, a tal punto que, en el caso que nos ocupa — concluye Saura-, "podemos afirmar sin temor a equivocarnos que estas pequeñas pinturas y dibujos fueron realizadas efectivamente por Torres Campalans, pintor imaginario, pintor inventado, y no por el escritor que lo vampirizó" (109).

\section{Consolidación del personaje, Desgaste del libro}

$\mathrm{Al}$ igual que sucediera con aquellos heterónimos pessoanos que acudían a despedirse de su creador en El año de la muerte de Ricardo Reis, de José Saramago, el Doppelgänger maxaubiano aprenderá pronto a vivir por su cuenta y no es que nadie pueda pararle los pies sino que quien más y quien menos va a ayudarle a caminar. Así, años después de que el diario Excélsior persista en el enredo al glosar la influencia de Campalans en la nueva pintura mexicana, especialmente en la obra de Tisner y de Vicente Rojo (Anónimo 1960: s. p.), este último regalará a Max Aub un gouache del artista descubierto, como quien no quiere la cosa, en una almoneda de Barcelona. Cabe decir que desde tiempo atrás venían sucediéndose hallazgos semejantes: cuando no aparecen epifánicamente en la correspondencia del autor, como es el caso del dibujo de un árbol navideño que acompaña a la misiva enviada al escritor por Joaquín Díez-Canedo en diciembre de 1958 y que éste asigna a la "época

\footnotetext{
${ }^{7}$ Sobre la importancia que Aub concedía a la obra de Duchamp, cfr. la entrada específica que le consagra en el archivo preparatorio para su monografía sobre Luis Buñuel (Aub 2013: 382-388).
} 
tradicionalista" del pintor (1958: 1), lo hacen acompañando artículos como el escrito por Emmanuel Roblès, donde figura un retrato del propio Roblès fechado ese mismo año (28) — recordemos que Campalans muere "oficialmente" en 1956-, o el publicado en 1965 en The economist, que incorpora un autorretrato cubista de Campalans firmado por Max Aub (Anónimo 1965: 869). La “colaboración” directa entre Aub y Campalans fructificará además, que sepamos, en el homenaje a la Banda de Bonnot que abre la segunda edición de Crímenes ejemplares (México: Finisterre, 1969) y en el poemario Versiones y subversiones (México: Alberto Dallal, 1971), donde el escritor aparece retratado por el pintor. De las secuelas que se sucederían una vez fallecido Aub merece la pena reseñar, por su desbordamiento del marco regular, la más reciente conocida, urdida por Juan Pedro Aparicio, Luis Mateo Díez y José María Merino al emplear un "Retrato de Sabino Ordás" pintado por Campalans como cubierta de Las cenizas del fénix (Madrid: Calambur, 2002), volumen recopilatorio de artículos publicados tras su retorno del exilio americano por dicho escritor leonés —un apócrifo empleado al alimón por los tres novelistas, en realidad.

Campalans, más otro que nunca del propio Aub, no sólo se dedicará a pintar por su cuenta sino que explotará la vena crítica mostrada en su "Cuaderno verde" en alguna que otra crónica aparecida en 1962 en la Revista de la Universidad de México (Torres Campalans: 24) y en artículos mensuales publicados en la misma revista entre mayo y agosto de 1966 e ilustrados por Leonora Carrington, no por él. Escapando a toda previsión, nuestro hombre-para-todo aparecerá incluso en Último cuaderno de Luis Álvarez Petreña, donde el protagonista imagina ser un Blaise Cendrars que "al regresar a París se hace amigo de Picasso, de Max Jacob, de Chagall, de Modigliani, de Jusep Torres Campalans" (Aub 1970b: 1098), siendo Cendrars, de hecho, "quien reveló el arte negro a Picasso y Campalans" (1101). En esta tesitura, resultando imposible prever por dónde iba a salir de nuevo el personaje, no parece descabellada la posibilidad de que Aub le reservase un lugar en su Luis Buñuel, pues, como escribiera Max-Pol Fouchet apenas iniciado el vuelo libre del personaje, "Jusep Torres Campalans no es un mito. Desengánense. Existe. Lo hemos visto. Un poco por todas partes. El último truco del señor Max Aub sería hacernos creer que no existe" (32). Pierre Joffroy, a esas alturas, no se cuestionaba ya ni su existencia ni su valía profesional, 
acababa yo de escribir esto cuando sonó el teléfono. Un marchante, muy versado en cuadros modernos, y además amigo mío, me dijo: "Parece que va a hacer usted algo sobre ese pintor desconocido, amigo de Picasso... Tengo algunas telas de la época en mi almacén. Tengo la impresión de que son suyas... En fin, usted verá...”.

Le dije que iría a verlo y colgué. Eran las 3 ó las 4 de la mañana. Un camión de las lecherías parisienses bajaba por la calle. A pesar mío, mi mirada se fijó en la pared de mi habitación, a la izquierda, entrando $-\mathrm{y}$ me dije que, verdadera e imparcialmente, ahí había sitio para un cuadro del gran Torres Campalans (42).

Los muy adeptos Fouchet y Joffroy publican sus artículos al calor de la impactante edición francesa de Gallimard, segunda en aparecer (Aub 1961). Que Aub lograse colocar su obra en el catálogo del sello más importante de Francia se debe, más que al regular contacto con su lugar de nacimiento, a la fuerte influencia de dos amigos ya citados, Jean Cassou, historiador de renombre y conservador jefe del Museo de Arte Moderno de París, y el todopoderoso André Malraux, Ministro de Cultura y destinatario de la dedicatoria que abría la edición primera. Será el jefe de gabinete de éste, André Beuret, quien le avance a Max Aub que, "según las últimas noticias, Claude Gallimard considera una edición de una calidad superior a la media, no digo edición de lujo porque sería demasiado, pero aún así algo esmerado..." (1). Quizá no quepa calificarla de edición de lujo, pero se le acerca: el libro, en tirada de 250 no venales numerados y 5000 ejemplares numerados — los 2000 del Fondo de Cultura Económica no lo estaban-, aumenta de tamaño, dobla el número de viñetas insertas en el cuerpo de texto, incluyendo algún que otro collage, e incorpora, adherido a las guardas posteriores, un pequeño volumen que remite en su portadilla a la muestra inicial —Catalogue de l'exposition Jusep Torres Campalans, Juillet 1958, Mexico - y reúne de forma exenta las reproducciones de 52 de los 58 cuadros que en aquella se distribuían a lo largo de todo el libro. Se constata así un salto cualitativo, un distanciamiento de la edición genuina, pero también de la coartada mimética que en buena medida la sostenía en pie: nada queda ya del formato físico a lo Skira y nada de sus recursos característicos, connotando quizá que la promoción del equívoco no ocupaba ya un lugar prioritario entre los propósitos maxaubianos. 
La odisea de Jusep Torres Campalans seguía su curso, después de todo. Aunque en Inglaterra los rechazos editoriales se habían sucedido desde que a finales de 1958 Thames \& Hudson, tras evaluar su libro "sobre el pintor mexicano (sic) Jusep Torres Campalans", considerase que "ofrecer al público inglés la vida romantizada de un artista que efectivamente es desconocido sería una proposición equivocada" (Clark 1958: 1), a mediados de 1961 Aub estaba en tratos para editarla en Alemania (Piper), Italia (Mondadori) y Suecia (Bonnier). Será la ya referida edición estadounidense, no obstante, la que siga a la francesa apenas un año después (Aub 1962b). El volumen disminuye un tanto de tamaño aunque retoma la cubierta estampada con el anagrama JTC y la sobrecubierta a todo color. También supone un cambio la reunión del conjunto de reproducciones en color y en blanco y negro en un pliego central de distinto gramaje y, sobre todo, el hecho de que éste lo abra una portada específica donde figuran los datos de aquella muestra prevista por el malogrado Henry Richard Town para la Tate Gallery en 1942. En general, la crítica estadounidense - de The New York Times Books Review a The Boston Sunday Globe y del Kansas City Star a la revista Time, aunque recurrimos al artículo "Move over, Picasso" aparecido en The Herald Tribune por su representatividad — ve en el libro,

una hilarante sátira sobre la erudición en arte (incluso las largas notas a pie de página llevan notas a pie de página), la promoción del arte, la crítica de arte, las batallas artísticas y sobre los propios artistas [...] El relato de la vida y los amoríos del artista en París es una parodia de todas las biografías de la Vie Bohème que han sido publicadas en ańos recientes (Genauer: 6).

Amén de permitir a la Biblioteca del Congreso en Washington enmendar el error de catalogación cometido años atrás con la edición mexicana (Sáenz: 493), ${ }^{8}$ este énfasis en el componente lúdico-burlesco del libro va a favorecer dos aspectos, a saber, el posicionamiento del

\footnotetext{
${ }^{8} \mathrm{Si}$ bien es comprensible un error de este tipo cuando Jusep Torres Campalans no era conocido en sus verdaderos términos, no lo es tanto que siga sucediendo: Ignacio Soldevila refiere que el Instituto Nacional del Libro Español catalogó la edición que en 1999 realizara Destino no en la sección 212: Literatura española. Novela y narración, como sería oportuno, sino en la 237: Biografías y memorias (2000: 189).
} 
libro en un mercado cultural bien diferente, ${ }^{9}$ y el refuerzo de la conciencia de superioridad del arte estadounidense del momento sobre la mítica vanguardia europea de anteguerra, aquí despojada de su aura y convertida, según se quería ver, en pintoresco cliché. Ni qué decir tiene que esta simplificación funcional deja a un lado mucho de lo ponderado hasta ahora: la dimensión objetual de la obra, su cuidada hechura estructural, el desdoblamiento creativo operado en ella y fuera de ella por Aub y, en definitiva, el uso de estrategias emanadas de dicha vanguardia que mostrarían su pervivencia bajo nuevas formas.

Aunque más por afinidad electiva que por propia decisión del autor, lo cierto es que justamente ese conjunto de rasgos aproximaría la obra al llamado libro de artista, modalidad creativa tan característicamente vanguardista como la simulación crítica, la interdisciplinariedad, el collage, el dispositivo escénico o el desvío, todos ellos referidos ya aquí por su concurrencia en Jusep Torres Campalans. Conviene subrayar cuanto antes que, si bien dicha denominación ha servido en más de una ocasión para designar las ediciones bibliofílicas - las promovidas por Kahnweiler o confeccionadas por el referido Stols, por ejemplo-, en modo alguno estaríamos aludiendo a ellas, pues, como se encarga de recordarnos la especialista Johanna Drucker, dichas ediciones "son producciones más que creaciones, productos más que visiones, ejemplos de un modelo, no cuestionamientos de su potencial formal o metafísico" (5). De hecho, señala, lo característico de los libros de artista es precisamente que "son casi siempre autoconscientes acerca de la estructura y el significado del libro" (3-4) en tanto que "conjunto de funciones estéticas, operaciones culturales, concepciones formales y espacios metafísicos", entendiéndolo además "como forma a interrogar, no meramente como vehículo de reproducción" (9). Nada hay de banal, de inocente o de accidental en el libro de artista: si se acoge al formato libro es para desentrañarlo y servirse creativamente de su especificidad, de su calidad ontológica, por así decir, y tal es el caso Jusep Torres Campalans.

\footnotetext{
${ }^{9}$ Es significativo que Herbert Weinstock, en la carta referida con anterioridad, comente al autor que "no deseamos etiquetarlo como una trampa", aunque, "por otro lado, no podemos publicarlo de modo que parezca estar intentando defraudar a compradores y lectores" (1962: 1). Muy otra había sido la opción del Fondo de Cultura Económica, que como única pista deslizaba en la solapa del libro una fugaz alusión a Otras novelas y cuentos de Max Aub y daba así a entender que Jusep Torres Campalans, de facto, lo era.
} 
No sólo es que Aub remede críticamente las monografías y las novelas de artista - ya Cervantes lo hizo con las novelas de caballerías—, sino que al hacerlo saca el formato libro de sus casillas y lo somete a un cuestionamiento que amplía su margen de acción hasta acercarlo al del arte mismo.

Ahora bien, lejos de cuestionar la forma libro para arrojarse plácidamente en brazos de un arte al uso, "estos libros son, por su existencia misma - remarca Anne Moegelin-Delcroix-, una crítica de la concepción tradicional de obra de arte en la medida en que persiguen hacer compatible la creación con la máxima difusión" (352). Se acabó la exclusividad, el mercadeo selecto, el juego cultual, parecen proclamar, y no ya porque, como le sucede a la obra de arte convencional en la "época de su reproductibilidad técnica" — Walter Benjamin dixit—, el desdoblamiento en matriz y reproducción múltiple resulte fatal para su condición aurática, sino, antes al contrario, porque en ellos no hay dualidad que valga y su condición distintiva e ineludible es justamente la multiplicidad. La irrupción de este modelo posee implicaciones de hondo calado, pues, como señala Rocío Gracia,

aceptar que un libro ostente la categoría de obra de arte, con todos sus aditamentos, supone haber hecho muchos de los deberes de un plan difuso iniciado hace más de un siglo. Supone, para empezar, haber apeado a la obra de arte de su posición sacralizada en su espacio "natural"; supone negarle valor a la "unicidad" como criterio; supone también anteponer el espectador, ahora lector, al artista convertido en autor (31).

Nada tiene esto de extraordinario si tomamos en cuenta que el receptor de cualquier obra de arte propiamente moderna se ve obligado a abandonar su atávico estatismo en favor de una acción creativa, y de hecho ya vimos hasta qué punto corresponde al lector de Jusep Torres Campalans armar los elementos que refieren al personaje y dotarlo de vida mediante la descarga eléctrica de la lectura. La diferencia viene marcada aquí por la complejidad de la obra y el consiguiente trabajo multidisciplinar del autor, pues solamente un letraherido como Aub, profundo conocedor y practicante de casi todos los géneros literarios, podría haber dado lugar a semejante despliegue de materiales de montaje — diarios, descripciones narrativas, anotaciones y diálogos a vuela pluma, citas eruditas, etc.- - pero tampoco nadie sin sus conocimientos 
en historia del arte, artes gráficas, dibujo y pintura podría haber conferido a Jusep Torres Campalans su insólito estatuto formal, esa amalgama plástica que constituye una y la misma cosa con todo lo anterior. Es la gestión equilibrada y eficaz de todo ese conjunto, en fin, lo que confiere a la obra su calidad de invención en sentido estricto, de libro de artista disfrazado de novela de artista o de autobiografía artística con apariencia de monografía sobre un artista ajeno, según se prefiera, porque todo eso y mucho más constituye el inagotable campo de fuerzas llamado Jusep Torres Campalans.

Triste es reconocer que la característica tensión entre forma y contenido caerá paulatinamente tras la publicación de Doubleday: a partir del episodio estadounidense, la historia de las ediciones de la obra será en gran medida la historia de una erosión, de un desdibujamiento, quizá entre otras razones porque el dispositivo escénico no volverá a formar parte del complejo Campalans. Como observa Dolores Fernández, las ediciones subsiguientes "siguen un formato de bolsillo que no tiene nada que ver con el lujo de la edición mexicana de 1958, la francesa de 1961 o la inglesa de 1962" (825). Si la meticulosa articulación de imagen y texto y el rigor editorial son rasgos medulares de Jusep Torres Campalans, y no mero ornamento, entonces toda edición posterior debiera haberlos preservado en la medida de lo posible, pero que tal no ha sido el caso salta a la vista al comprobar cómo la mayoría de las ediciones posteriores ha trastocado la obra mediante la asfixia del texto, el descuido en la maquetación, la supresión del color o la drástica reducción del número - cuando no completa eliminación— de imágenes, al punto de hacer de ella una pieza literaria como cualquier otra. ${ }^{10}$ Quizá poco importe este desgaste, al fin y al cabo, porque las ediciones, mejores o peores pero en formatos accesibles y en múltiples lenguas, iban a convertir la fábula inicial en mito duradero; no deja de ser significativo, en este sentido, que tras una vida plena de acontecimientos, una inten-

${ }^{10}$ Comenzando por la italiana de Mondadori (Milán, 1963), que pese a la buena presentación reduce la maquetación al mínimo y no incluye ninguna viñeta y sólo nueve cuadros al final, y continuando por las versiones de Aguilar (México D. F., 1970, en volumen conjunto con otras obras del autor), Lumen (Barcelona, 1970), Alianza (Madrid, 1975), Plaza \& Janés (Barcelona, 1985), Sellerio (Palermo, 1992), Eichborn (Fráncfort del Meno, 1997), Gutenberg (Fráncfort del Meno/Viena, 1997), Destino (Barcelona, 1999), Piper (Múnich, 1999), Arte y Literatura (La Habana, 2002) y RBA (Barcelona, 2011, en volumen conjunto con Vida y obra de Luis Álvarez Petreña). 
sísima actividad cultural y la autoría de cientos de textos de todo tipo, la nota necrológica publicada en el diario Excélsior viniera encabezada por el titular "Un paro cardiaco causó la muerte a Max Aub, autor de Jusep Torres Campalans" (Anónimo 1972: s. p.).

\section{Bibliografía}

\section{Correspondencia y notas inéditas}

Todas las referencias recogidas en este apartado se encuentran depositadas en el Archivo Max Aub de la Fundación Max Aub de Segorbe (Castellón, España) e incorporan su correspondiente código de clasificación.

Aub, Max. Carta a Camilo José Cela del 17 de junio 1958a [C.4-13/10a]. Aub, Max. Carta a Camilo José Cela del 10 de julio 1958b [C.4-13/12]. Aub, Max. Carta a Carlos Barral del 23 de diciembre 1958c [C.2-12/7a]. Aub, Max. Carta a Carlos Barral del 27 de diciembre 1958d [C.2-12/8a]. Aub, Max. Carta a Herbert Weinstock del 6 de febrero 1962a [C.5-13/25a]. Aub, Max. Texto para la edición de Lumen de Jusep Torres Campalans 1970a [C.22-9/2].

Aub, Max. Carta a Carmen Balcells del 16 de junio 1971a [C.2-3/162a]. Beuret, André. Carta a Max Aub del 16 de mayo 1960 [C.9-8/41]. Clark, James. Carta a Max Aub del 12 de noviembre 1958 [C.4-27/1]. Díez-Canedo, Joaquín. Carta a Max Aub del 24 de diciembre 1958 [C.6$4 / 5]$.

Weinstock, Herbert. Carta a Max Aub del 1 de febrero 1962 [C.5-13/23a].

\section{Libros, artículos y reseñas}

Anónimo. "Se agota el libro del Sr. J. T. Campalans", en Excélsior, México, 11 de julio 1958a: 9.

Anónimo. "Las alegres bromas de dos pintores catalanes hacen reír al mundo", en Novedades. México en la Cultura, México, núm. 487, 14 de julio 1958b: 1 y 3 .

Anónimo. "El escándalo artístico de J.T. Campalans", en Excélsior, México, 22 de julio 1958c: s. p. 
Anónimo. "Influencia de un cuadro de Torres Campalans", en Excélsior, México, 5 de junio 1960: s. p.

Anónimo. "Ghostly Genius of Catalonia", en The economist, Nueva York, 4 de septiembre 1965: 869.

Anónimo. "Un paro cardiaco causó la muerte a Max Aub, autor de Jusep Torres Campalans", en Excélsior, México, 23 de julio 1972: s. p.

Aub, Max. Jusep Torres Campalans. México: Fondo de Cultura Económica, $1958 \mathrm{~b}$.

Aub, Max. Jusep Torres Campalans. Trad. Alice Gascar y Pierre Gascar. París: Gallimard, 1961.

Aub, Max. Jusep Torres Campalans. Trad. Herbert Weinstock. Nueva York: Doubleday, $1962 \mathrm{~b}$.

Aub, Max. Hablo como hombre. México: Joaquín Mortiz, 1967.

Aub, Max. Novelas escogidas. México: Aguilar, 1970b.

Aub, Max. La gallina ciega. México: Joaquín Mortiz, 1971 b.

Aub, Max. Conversaciones con Buñuel. Madrid: Aguilar, 1985.

Aub, Max. Diarios 1939-1972. Barcelona: Alba, 1998.

Aub, Max. Luis Buñuel, novela. Granada: Cuadernos del Vigía, 2013.

Bonet, Juan Manuel. "Prólogo", en AA.VV. Jusep Torres Campalans. Ingenio de la vanguardia. Madrid: SECC / MNCARS, 2003: 13-14.

Camps, Francisco. "Max Aub y Jusep Torres", en Excélsior, México, 20 de agosto 1958: s. p.

Cassou, Jean. "Cet homme est le héros du canular le plus vertigineux du siècle: toute la realité est peut être imaginaire”, en Arts, París, núm. 813, 1961a: 1 .

Cassou, Jean. "Jusep Torres Campalans. Le Rimbaud de la peinture moderne”, en Bulletin N.R.F., París, núm. 158, 1961 b: 9 y 14.

Chabrun, Jean-François. "Max Aub: J'ai mystifié deux continents avec mon faux super Picasso", en Télé 7 Jours, París, núm. 57, 1961: 30-31.

Corella, Miguel. El artista y sus otros. Max Aub y la novela del artista. Valencia: Biblioteca Valenciana / Generalitat Valenciana, 2003.

Couffon, Claude. "Pour connaître Jusep Torres Campalans", en Les lettres nouvelles, París, 11 de marzo 1961: 183-185.

Drucker, Johanna. The Century of Artist's Books. Nueva York: Granary, 2007. Fernández, Dolores. "La leyenda de Jusep Torres Campalans", en Cecilio Alonso, ed. Actas del Congreso Internacional "Max Aub y el laberinto español" (Valencia-Segorbe, 13-17 diciembre 1993). Valencia: Ayto. de Valencia, 1996: 825-858.

Fouchet, Max-Pol. "Fable. J.T. Campalans par Max Aub”, en L'Expresss, París, 6 de abril 1961: 32. 
García Tarrés, Jaime y Carlos Fuentes. "Galeras” [facsímil], en Manuel García, ed. Max Aub. Jusep Torres Campalans. Valencia: Generalitat Valenciana, 2000: 195-210.

Genauer, Emily. "Move over, Picasso", en The Herald Tribune, Nueva York, 28 de octubre 1962: 6.

Giner de los Ríos, Bernardo. "Max Aub: tipógrafo y editor. Una visión parcial", en Cecilio Alonso, ed. Actas del Congreso Internacional "Max Aub y el laberinto español" (Valencia-Segorbe, 13-17 diciembre 1993). Valencia: Ayto. de Valencia, 1996: 55-67.

Gracia, Rocío. "Calendario de producción”, en José Arturo Rodríguez, ed. Hojeando... Cuatro décadas de libros y revistas de artista en España. Madrid: SEACEX, 2008: 31-35.

Huici, Fernando. "Ingenio de la vanguardia", en AA.VV. Jusep Torres Campalans. Ingenio de la vanguardia. Madrid: SECC / MNCARs, 2003: 17-40.

Joffroy, Pierre. "Il est photographié ici à côte de Picasso et pourtant... cet homme n'existe pas”, en Paris-Match, París, 18 de marzo 1961: 38-42.

Mainer, José Carlos. "La ética del testigo: vanguardia como moral en Max Aub", en Cecilio Alonso, ed. Actas del Congreso Internacional "Max Aub y el laberinto español" (Valencia Segorbe, 13-17 diciembre 1993). Valencia: Ayto. de Valencia, 1996: 69-91.

Mazars, Pierre. "J'ai fait rigoler Picasso, raconte Max Aub”, en Le Figaro Littéraire, París, 11 de marzo 1961: 11.

Moegelin-Delcroix, Anne. Sur le livre d'artiste. Articles et écrits de circonstance (1981-2005). Marsella: Le mot et le reste, 2006.

Nelken, Margarita. “¡Respeto al arte!”, en Excélsior, México, 20 de julio 1958: s. p.

Oleza, Joan. "El apócrifo, prototipo de una subjetividad en crisis", en $A s$ clepio, $\mathrm{n}^{\mathrm{a}} 65$ (2), julio 2013. Artículo en línea disponible en: <http:// dx.doi.org/10.3989/asclepio.2013.15>.

Pérez, Carlos. "Max Aub en la tierra de la modernidad imposible", en AA.VV. Jusep Torres Campalans. Ingenio de la vanguardia. Madrid: SECC / MNCARS, 2003: 63-72.

Raynal, Maurice. Picasso. Ginebra: Skira, 1953.

Roblès, Emmanuel. "Trois romanciers espagnols et deux poètes algeriens”, en Algerie, Orán, julio 1961: 28-29.

Rodríguez, Joaquina y Alejandra Herrera. Relatos y prosas breves de Max Aub. México: Universidad Autónoma Metropolitana, 1993.

Rosell, María. Los poetas apócrifos de Max Aub. Valencia: Universidad de Valencia, 2012.

Sáenz, Pilar. "Ambigüedad, ficción y metaficción en Jusep Torres Campalans", en Cecilio Alonso, ed. Actas del Congreso Internacional "Max Aub y el 
laberinto español" (Valencia-Segorbe, 13-17 diciembre 1993). Valencia: Ayto. de Valencia, 1996: 488-493.

Saura, Antonio. "El pintor imaginario", en Ignacio Soldevila y Dolores Fernández, eds. Max Aub: veinticinco años después. Actas del curso de verano en El Escorial. Madrid: Editorial Complutense, 1999: 89-110.

Soldevila, Ignacio. La obra narrativa de Max Aub (1929-1969). Madrid: Gredos, 1973.

Soldevila, Ignacio. "Bibliografía de Max Aub”, en Manuel García, ed. Max Aub. Jusep Torres Campalans. Valencia: Generalitat Valenciana, 2000: 179-217.

Torres Campalans, Jusep [Max Aub]. "Vincent, le Rouge", Revista de la Universidad de México, México, noviembre 1962: 24.

Van Dijk, Cornelis. Alexandre A.M. Stols 1900-1973 uitgever/typograaf. Een documentatie. Zutphen: Walburg, 1992.

Vílchez, Carmen E. "Literatura y pintura. Jusep Torres Campalans, una novela cubista”, en Arbor, Madrid, núm. 726, julio-agosto 2007: 503-510.

Zendejas, Francisco. “Jusep Torres Campalans”, en Excélsior, México, 12 de julio 1958: 8 . 